\title{
Museo de la Memoria de Lima: El caso "Josefina Ramos de Cox"
}

Inés del Águila Ríos

Museo de Arqueología "Josefina Ramos de Cox"

El artículo describe la historia del museo y los retos de construcción de una propuesta museológica/museográfica que permita una adecuada comunicación educativa con los ciudadanos del Centro Histórico de Lima y los visitantes del Perú.

Museología, red, Centro Histórico de Lima, experiencia museal

The article describes the history of the museum and the challenges of building a museology / museum proposal to allow proper communication with the public education of the Historic Center of Lima, Peru visitors.

Museology, network, Historic Centre of Lima, museum experience

\section{Perfil histórico y bases fundacionales}

El Museo de Arqueología "Josefina Ramos de Cox" es un museo universitario de carácter histórico-arqueológico fundado en 1971 por la doctora Josefina Ramos de Cox. Es asimismo una de las Unidades de Servicios Académicos, que pertenece al Instituto Riva Agüero, Escuela de Altos estudios de la Pontificia Universidad Católica del Perú.

Los principales aspectos considerados para justificar la fundación del museo, como espacio de investigación, conservación, difusión y educación sobre la memoria de Lima y el Perú fueron:

- El potencial científico de sus colecciones procedente de excavaciones arqueológicas en los valles de los ríos Rímac, Lurín, y en la casona O’Higgins.

La singularidad de las colecciones que permiten leer contextos inexistentes hoy en Lima por el iconoclasta avance urbano y que se exhiben sólo en nuestro museo.

- Su primera sede, la casona histórica O’Higgins' ${ }^{1}$, (vivienda que alquilara el ilustre prócer de la emancipación latinoamericana y libertador de Chile don Bernardo O'Higgins) cuya ubicación en la tradicional calle Espaderos del Jirón de la Unión, en el centro histórico de la capital del Perú, permitió la primera experiencia museal.

1 Llamada así por que aquí vivió y murió don Bernardo O'Higgins, precursor de la emancipación americana y Supremo Director de Chile proclamada su independencia. En 1989 esta casona republicana fue declarada monumento histórico según resolución 009-89/ INC. Aquí funcionó el museo de arqueología "Josefina Ramos de Cox" antes de su traslado a Plaza Francia en 2010. 

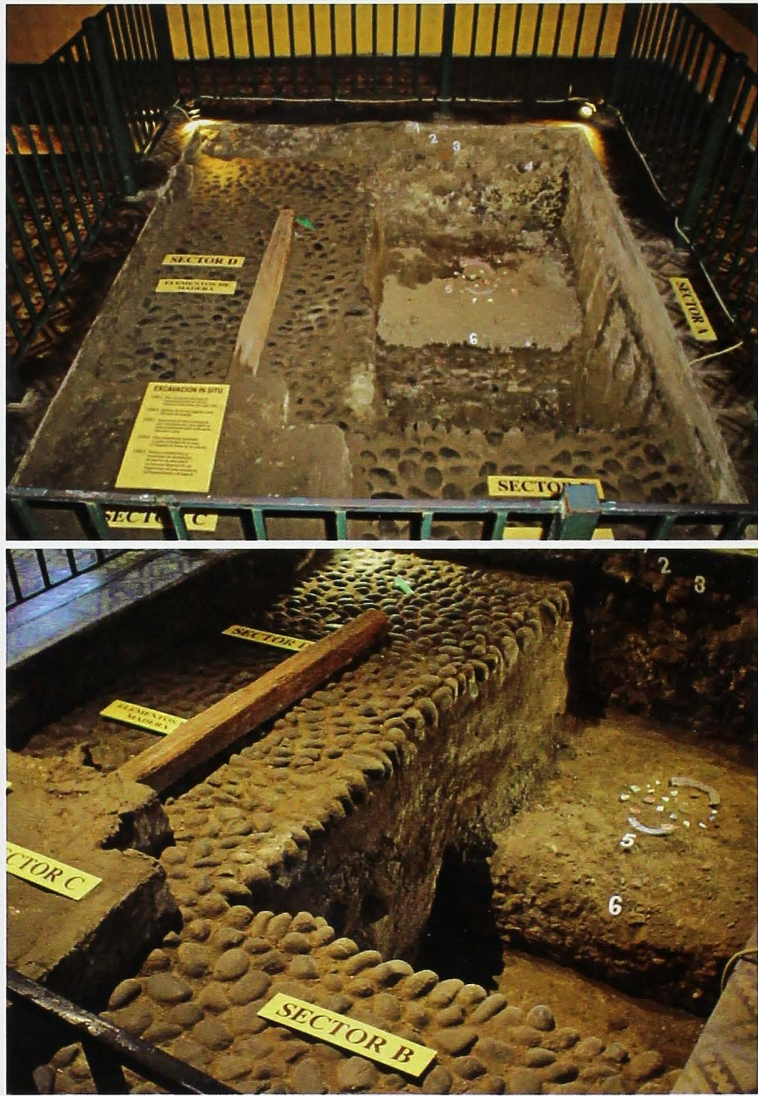

Contexto excavado en la casa O'Higgins que muestra las sucesivas ocupaciones de la casona. El piso empedrado corresponde a la casona de la época colonial sobre la cual se edificó la casona republicana. 


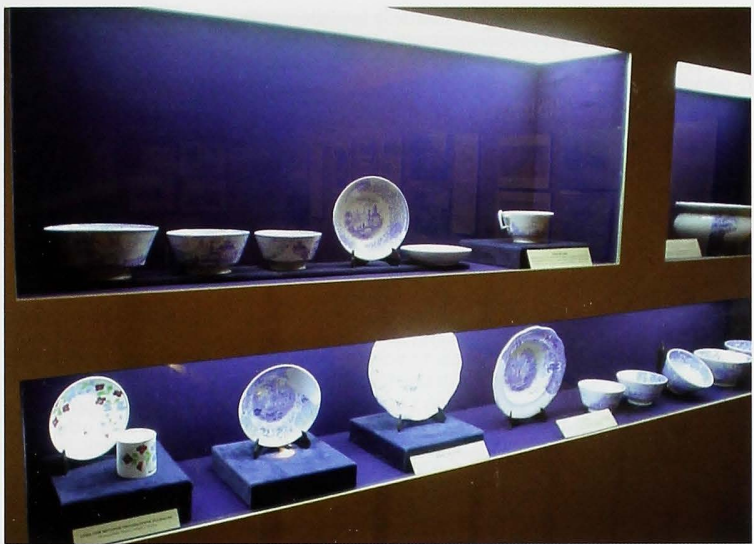

Conjunto de loza de la fábrica inglesa Davenport y Muleteer de los siglos XVIII y XIX. Descubierta durante las excavaciones en la casa O'Higgins.

- La sede actual en la histórica Plaza Francia y en el edificio de los primeros años fundacionales de la Pontificia Universidad Católica, sigue constituyendo un territorio que nos vincula con la ciudad de Lima y su gente que vive y es ciudadano de a pie en el Centro Histórico.

\section{El pensamiento museológico de su fundadora}

Desde su fundación, el museo fue concebido como un espacio dedicado a fomentar entre los visitantes la reflexión respecto del devenir histórico cultural de la ciudad de Lima.

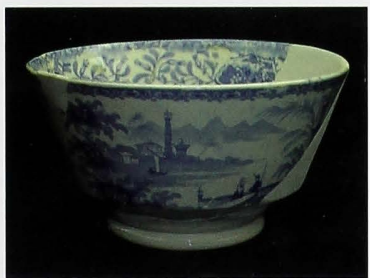

Tazón de loza color blanco con diseños orientales en color azul de la fábrica inglesa Daventport, modelo Erika, encontrado en las excavaciones en la casona O'Higgins.

La doctora Cox en el año 1969 al solicitar la creación del museo², señaló que el Seminario de Arqueología podía presentar un panorama de más de 9,000 años de historia de la capital del Perú y de los otros pueblos que pasaron por Lima hasta la llegada de los españoles. Esta historia debía mostrar la vida de Lima en sus aportes locales, su integración regional, nacional y universal, porque sus colecciones procedentes de los trabajos arqueológicos en el sitio Tablada de Lurín y el Complejo Arqueológico Huacas Pando contenían evidencias de procesos históricos desde el arcaico hasta la llegada de los españoles en el siglo XVI.

2 Ramos Josefina, 1969. "Carta al Rvdo. Padre Felipe Mac Gregor, S.J. Universidad Católica del Perú. 
Pensar el museo a partir de las premisas de la fundadora y desde el museo, pensar el Perú con la lectura de nuestras colecciones excavadas en Maranga y en casona O'Higgins, nos condujo a entender y vivir la experiencia del devenir histórico de la ciudad de Lima mediante miradas de larga duración, que abarcan desde la época prehispánica, hasta los primeros años de la República.

\section{La experiencia museal en la casa histórica O'Higgins}

El 13 de Julio de 1974 fallece la doctora Josefina Ramos de Cox y en acto de reconocimiento, las autoridades del Instituto Riva Agüero a solicitud de los miembros del Seminario de Arqueología trasmiten al Rector el deseo de que el museo lleve el nombre de su fundadora. Con acuerdo del Consejo Universitario de la Pontificia Universidad Católica del Perú, declaran que en adelante el museo se denominará Museo de Arqueología "Josefina Ramos de Cox".

Hasta 1977 el museo continuó el programa diseñado por la doctora Cox. Durante este tiempo el museo sigue atendiendo a los visitantes de la exposición" Lima Nueve mil años" los días sábados y domingos mediante turnos de voluntarios, conformado por estudiantes e investigadores del Seminario de Arqueología y coordinados por la doctora Mercedes Cárdenas. Más adelante la coordinación y la responsabilidad de implementar exposiciones recae en Inés del Águila, y cierra el ciclo de atención al público al final de los ochenta el señor Rolando Tamashiro.

Hacia los años noventa, periodo que coincide con la creación de la Coordinación de Unidades de Servicios Académicos, del Instituto Riva Aguiero, el MAJRC dependerá directamente del Instituto Riva Agüero. En este contexto la dirección del Instituto Riva Agüiero encarga reabrir el museo con un programa de exposiciones de carácter permanente y temporales, que incluirá algunas itinerantes.

La reapertura del museo intensificó las labores de investigación arqueológica, museológica y arquitectónica con el fin de elaborar el guión científico y el guión museográfico de la futura exposición permanente. La meta es iniciar la atención al público de Lima con la inauguración de la exposición titulada Hatun Maranga.

La investigación arquitectónica de la casona, se realizó con participación de Liliana Aybar y Martha Collazos tesistas de la Universidad Ricardo Palma que definieron las bases teóricas de la puesta en valor de la casona, propuesta, que captó el interés del gobierno de Chile y dio lugar a los primeros trabajos de la puesta en valor.

El estudio de públicos del entorno más cercano al museo se realizó con el apoyo de la Asociación de Comerciantes del Jirón de la Unión y fue fundamental. Nos permitió entender nuestro entorno humano y territorial, saber que somos parte de un un territorio histórico -el Jirón de la Unión-, donde transeúntes y trabajadores de los centros comerciales son los principales actores con quienes construir la lectura patrimonial del museo y pensar Lima en el Perú.

El reto de pensar Lima y el Perú implicó elegir los pensadores sobre la idea del Perú, y su inclusión en el enfoque museológico/pedagógico del MAJRC, sin dejar de indagar y elegir pensadores sobre los museos del Perú. Entre las reflexiones y serias críticas en torno al origen y trayectoria de los museos elegimos las ideas de Castrillón Vizcarra ${ }^{3}$ (1986) quien señala, "que la promesa del museo peruano es quizá el más antiguo de los ofrecimientos que nos ha hecho el Estado republicano: desde 1824 existe como proyecto y sin embargo no logra realizarse plenamente". 
Desde otra óptica Ravines (1989) hace hincapié en los museos arqueológicos “donde la contemplación y exaltación del pasado crean y fortalecen el patriotismo y contribuyen al sustento de una idea nacional".

Sobre la idea del Perú, resultó interesante para nuestros fines museológicos el pensamiento de Karen Sanders ${ }^{4}$ (1999) que al estudiar a los grandes pensadores sobre el Perú y su destino, entre ellos, José Carlos Mariátegui, Víctor Andrés Belaunde y Víctor Raúl Haya de la Torre señala:

que dichos autores tienen intereses e ideas comunes sobre el Perú. Finalmente plantea que en el Perú hace falta aceptar francamente la diversidad cultural y la realidad de un pasado complejo y turbado, para ella la identidad nacional es un proyecto abierto compuesto de capas múltiples y tradiciones diversas.

En esta línea de análisis el MAJRC consideró importante seleccionar las ideas sobre el Perú y la peruanidad vertidas por los siguientes pensadores:

Víctor Andrés Belaunde ${ }^{5}$ dice: "La peruanidad es una síntesis comenzada pero no concluida. El destino del Perú es continuar realizando esa síntesis".

José Antonio del Busto 6 (1998) nos dice:

que el Perú como nación es un conjunto de pueblos con un pasado, un presente, y un futuro común que, por encima de todo vínculo posee el de la conciencia nacional, que consiste -según nuestro autor- en ser peruano saberse peruano sentirse peruano y querer seguir siendo peruano.

Finalmente, es interesante el mensaje que sobre el tema plantea el historiador doctor José de la Puente y Candamo7 (1992) quien postula "fortalecer nuestro conocimiento y creencia en la vocación mestiza integradora del Perú".

En 1994 al inaugurarse Hatun Maranga se reanuda la atención al público, acorde con los nuevos avances de la disciplina museológica y con el énfasis puesto en la función sociocultural del museo. En este marco conceptual el MAJRC inicia el liderazgo de los programas educativo-culturales en permanente coordinación con la Asociación de Comerciantes del jirón de la Unión, con las autoridades educativas del sector, con las autoridades municipales distritales y con la Municipalidad Metropolitana de Lima.

Como se indicó líneas arriba la exposición de inauguración tiene como título Hatun Maranga (El Gran Marai o batán) y pone de relieve la valoración de la memoria de los pueblos que habitaron Lima desde los periodos tardíos prehispánicos y su evolución hacia los primeros años de la vida republicana. Tiene como particularidad ser una muestra en serie, estrategia pedagógica que narra secuencialmente el quehacer cultural de los Maranga en Lima y sus interrelaciones con los otros pueblos del Perú acorde a las expectativas del interés de los migrantes de provincias en la capital que buscan insertarse en la sociedad a través de su desarrollo cultural.

Las exposiciones temporales complementan el discurso de la exposición permanente para enfatizar temáticas relacionadas con el paisaje de nuestra ciudad limeña donde las imponentes pirámides de barro de nuestros ancestros reclaman formar parte de la memoria colectiva de las nuevas gentes que habitan Lima. Aspiramos a generar entre nuestros

4 Sanders, Karen. 1999. Nación y Tradición, Cinco discursos en torno a la Nación Peruana. p.445.

5 Belaunde, Víctor Andrés. 1968. Peruanidad. pp. 141-142.

6 Busto D. José Antonio del. 1998. Tres Ensayos Peruanistas. p.10.

7 Puente C. José de la. 1992. La identidad Peruana en lo hispanoamericano. p.40. 
visitantes la valoración de ellas como emblemas de la patria antigua y evitar de este modo su depredación y olvido.

Queremos que el territorio de la ciudad de Lima pueda dar oportunidad a la lectura de sus cambios pero con continuidad. Esta intensa relación del museo con la sociedad conduciría a la creación de la Red de Cultura y Comercio en alianza con la Asociación de Comerciantes del Jirón de la Unión, La Red de museos del Centro histórico de Lima nucleando a los directores de museos ubicados en el Centro Histórico.

\section{Los visitantes del museo y la idea del Perú}

Las imágenes estadísticas que observamos ilustran el primer acercamiento sistemático desde la reapertura del museo en el año 1994-95. Es la primera impresión de los ciudadanos de a pie en Lima y de aquellos que irán siendo cautivados por un museo en el Jirón de la Unión.

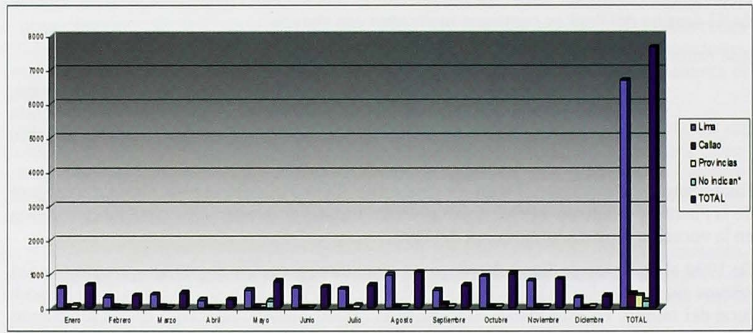

Cuadro estadístico de visitantes del MAJRC 2005

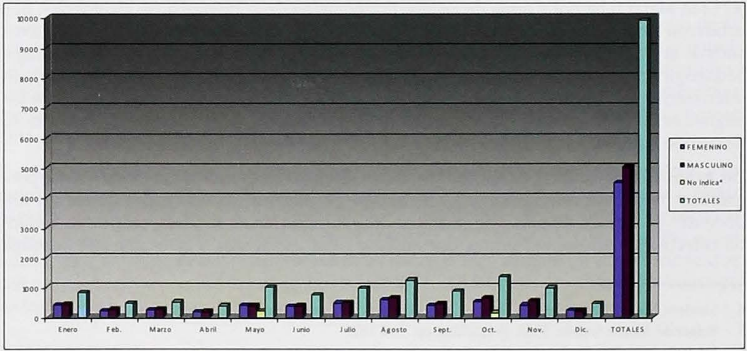

Cuadro estadístico de visitantes por género en el MAJRC/2005. 


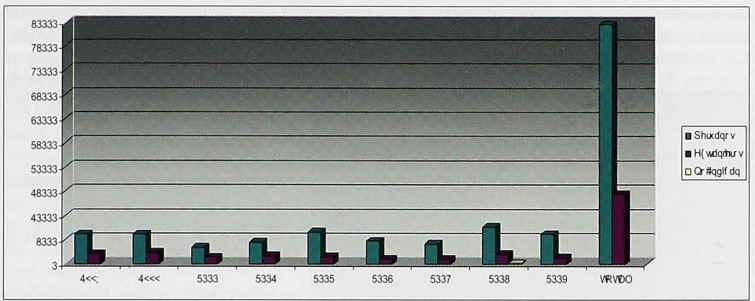

Cuadro estadístico general de visitantes por años según nacionalidad en el MAJRC/1998-2006.

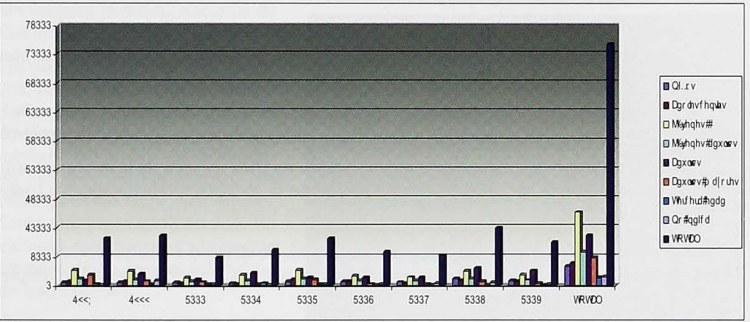

Cuadro estadístico general de visitantes por años según edades en el MAJRC/1998-2006.

En el Museo Josefina Ramos de Cox, nos interesamos en seguir sistemáticamente las opiniones vertidas por nuestros visitantes. La lectura de estas opiniones dejó entrever cómo determinadas ideas se repetían y era posible clasificarlas y categorizarlas. Ante esta posibilidad se inició la clasificación y su inclusión en categorías implícitas y recurrentes.

Desde 1995 hasta el 2002 es importante resaltar las siguientes categorías inferidas de las opiniones:

- Originalidad del museo,

- Valoración del pasado y el patrimonio arqueológico,

- Impacto museológico y museográfico,

- Descubriendo el pasado de Lima,

- El museo creando conciencia cultural,

- El museo como lugar de descanso e interioridad. 
La estadística de visitantes permite observar nuevas gentes que ingresan a nuestro museo y asimismo cómo se fue construyendo, a partir de ello, el público del MAJRC. Las opiniones de nuestros visitantes, que permitió establecer categorías, contienen un sistema de valoraciones del pasado que se resaltan las raíces culturales e históricas de nuestra personalidad nacional, también bajo esta connotación surge la valoración del mestizaje.

Presentamos el sistema de valoraciones inferidos de las opiniones:

"Interesante y didáctico para las personas no vinculadas al mundo de la arqueología".

"Es muy agradable encontrarme con lugares como este, donde se mantiene la memoria de nuestros pueblos".

"Yo vivo cerca de la Huaca Mateo Salado y creo haber comprendido mi verdadero origen al haber visto lo que sucedió en mi casa hace muchos años".

"Como visitante limeña ahora puedo llevarme algo de cultura en un mundo que es muy hostil como Lima y el Jirón de la Unión de hoy... la belleza de la casona y sencillamente encontrar historia que nos conecta con el pasado real nos infunde la valoración de esas personas que vivieron alguna vez. Espero que este lugar nunca se cierre".

"El museo es un oasis en medio del laberinto. Es un alivio para la cultura, muy bueno" (abogada).

"Lima se merece un museo propio que retrate la larga historia de este valle y que inspire a la población a proteger los monumentos que quedan” (ingeniero).

"Da mucha pena que la gente que ha nacido en Lima no sepa de la impresionante cultura que posee, y que ya casi totalmente la olvidaron, felicitaciones a todos los que hicieron posible este museo" (Lic. en Turismo - Cusco).

\section{Contribuyendo al fortalecimiento de la peruanidad. Programas socioculturales}

En concordancia con la tarea de responsabilidad social que realiza la PUCP, el MAJRC implementó dos grandes programas:

\section{El Museo y su entorno}

Que tiene como objetivo profundizar la función sociocultural y educativa de los museos. Comprende tres actividades vinculadas con las expectativas pedagógicas del público del entorno (centro histórico) y las tareas cívicas de las autoridades representativas del gobierno central y las autoridades locales.

Son tres las actividades que conforman este primer programa:

1. Tertulias museo pedagógicas. Reunión de docentes del centro histórico para dialogar sobre el uso didáctico del Museo con fines de educación formal y no formal.

2. Jirón de la Unión; rastros y rostros de un jirón histórico y cultural. Actividad de carácter museográfico que consiste en emblematizar visualmente el Jirón de la Unión exponiendo testimonios seráficos de su historia monumental y de la vida cotidiana acaecida en este espacio. Se trata de brindar cultura a pie desbordando los ambientes del museo y poniendo al alcance de toda la memoria de Lima y su patrimonio.

3. Red y diálogos de museos del Centro histórico. Es la creación de conexiones entre los museos del Centro histórico, para conformar una comisión con representantes de dichos museos que trabajen juntos en el perfeccionamiento técnico profesional de 
quehacer museístico y en programas de carácter cívico/cultural orientadores de la opinión pública en temas de conciencia histórica, identidades y conciencia cívica. Asimismo, esta red deberá buscar el apoyo financiero para dichas actividades.

\section{Educando en la conservación} del patrimonio arqueológico en Lima

Actividad dirigida a alertar y asesorar a las autoridades municipales, vecinales y educativas sobre la defensa y conservación de los monumentos arqueológicos que todavía quedan en pie en la ciudad de Lima y alrededores. Comprende visitas de campo, exposiciones, mesas redondas $y$ elaboración de propuestas para la puesta en valor de dichos monumentos las cuales se elevaron al entonces Instituto Nacional de Cultura.

Los programas ejecutados, a la fecha, han comprometido la acción de vecinos, educadores y autoridades relacionadas con los monumentos arqueológicos ubicados en San Juan de Lurigancho, Los Olivos, Pueblo Libre, San Miguel, Santa Eulalia y Lima Cercado. Un ejemplo excepcional es la puesta en valor de las huacas del Parque de las Leyendas.

Finalmente en el año 2006 se inician las tareas de puesta en valor de la Casona Histórica O'Higgins y se suspende la atención al público en las salas de exposición, más la necesidad para seguir actuando en beneficio de la sociedad y motivados por las alianzas pactadas, el MAJRC crea y reinventa permanentemente los programas socioculturales que siguen cumpliendo sus fines patrimoniales, sirviendo y aprendiendo siempre motivados por las alianzas arriba mencionadas. Estas actividades continúan en su nuevo local ubicado en la Plaza Francia, en el edificio donde funcionaron las primeras aulas de la Pontificia Universidad Católica del Perú.

\section{A modo de conclusión: El Jirón de la Unión y su gente}

La ubicación del museo en el Jirón más importante del Centro histórico, por su carácter histórico como centro comercial y tránsito permanente de los habitantes de Lima, especialmente de las zonas o distritos más poblados, se ha convertido en una oportunidad para fomentar desde el museo el convivio de todas las sangres.

Es nuestro objetivo atraer este público al museo y también por ello, venimos implementando el desborde del museo hacia algunos locales comerciales que se han inscrito en la 
red de cultura y comercio para participar en la emblematización del Jirón de la Unión. El programa diseñado para este fin lo hemos denominado "estaciones culturales en centros comerciales". De esta manera los locales comerciales se convierten en extensión del museo y brindarán información del devenir de Lima a sus clientes.

Como museo universitario y de carácter arqueológico, nuestra tarea de investigación es una línea que atraviesa las diferentes actividades y funciones que realiza el museo. No olvidamos que las colecciones son un laboratorio para ampliar los conocimientos especializados que se derivan de su estudio, pero también en nuestro caso responde a una de las formas de leer el patrimonio arqueológico. Nos preguntamos con Vich (2006) ¿qué sentido tiene, por ejemplo, gestionar bien un museo si no hay en él una buena narrativa del pasado que permita influir políticamente en el presente del visitante?

En torno a estas preocupaciones venimos construyendo un marco de referencia para el uso educativo de los objetos arqueológicos y a este enfoque lo llamamos "arqueología aplicada a la educación social".

Otra actividad que se investiga para responder a las expectativas pedagógicas del público (su interés por aprender), es la tarea museográfica. Pretendemos crear un modelo en el que el esquema del proyecto museográfico, valga la redundancia, sea pedagógico en la medida que ello representa el respeto a la estructura mental de nuestros visitantes. Nuestro guión museográfico debe responder a las grandes interrogantes del público sobre sus preocupaciones como ciudadano, y como peruano.

Finalmente queremos que el museo sea una ventana y una tribuna a la vez, en el que todos contribuyan a fortalecer nuestra peruanidad mediante el diálogo intercultural. 


\section{Bibliografía}

Águila Ríos, Inés del

2009 Museos del Centro Histórico de Lima: una propuesta compartida.

2004 Memoria del Museo Josefina Ramos de Cox. Lima: IRAMMAJRC.

1987 Memoria del Museo Josefina Ramos de Cox 1998-2004. Lima: IRAMAJRC.

Águila Ríos, Inés del et al.

2009 Jirón de la Unión. Derroteros de un itinerario cultural en Lima.

Belaunde, Víctor Andrés

1968 Peruanidad. Lima: PUCP, Instituto Riva-Aguiero.

Busto Duthurburu, José Antonio del

1998 Tres ensayos peruanistas. Lima: PUCP. Instituto Riva-Agüero.

\section{Castrillón Vizcarra, Alfonso}

1986 Museo Peruano: utopía y realidad. Lima: Industrial Gráfica.

1983 La museografía como método. Lima: UNMSM.

\section{Holguín Callo, Oswaldo}

2005 El largo camino de la nación peruana (siglo XX). En Revista Histórica. Tomo XLII (2005-2006). Lima: Instituto Histórico del Perú. pp. 65-95.

\section{ICOM - UNESCO}

2007 Nuestra visión global. En pro de un mundo en el que se valore universalmente la importancia del patrimonio natural y cultural. París: ICOM.

Puente Candamo, José A. de la

1992 La identidad peruana en lo hispanoamericano. Piura: Universidad de Piura.

Riva-Agüiero, José de la

1960 Afirmación del Perú. Lima: PUCP.

Sanders, Karen

1997 Nación y tradición: cinco discursos en torno a la nación peruana, 1885-1930. Lima: PUCP, Instituto Riva-Agüero; México, D.F: Fondo de Cultura Económica.

Vich, Víctor y Guillermo Cortés (editores)

2006 Políticas culturales: ensayos críticos. Lima: IEP, INC, OEI. 
